http://dx.doi.org/10.1590/brag.2014.022

\title{
Herança da resistência do acesso de melancia PI 595201 a isolado de PRSV-W do Estado do Tocantins
}

\author{
Anatércia Ferreira Alves ( $\left.{ }^{1 *}\right)$; Ildon Rodrigues do Nascimento (1); César Augusto Ticona-Benavente $\left({ }^{2}\right)$; \\ Marcos Ventura Faria ( ${ }^{3}$ ); Renato de Almeida Sarmento ('); Antônia dos Reis Figueira ( ${ }^{4}$ ); \\ Wilson Roberto Maluf $\left({ }^{2}\right)$ \\ (1) Universidade Federal do Tocantins (UFT), Produção Vegetal, Caixa Postal 66, 77402-970 Gurupi (TO), Brasil. \\ (2) Universidade Federal de Lavras (UFLA), Departamento de Biologia, Caixa Postal 3037, 37200-000 Lavras (MG), Brasil. \\ (3) Universidade Estadual do Centro-Oeste (UNICENTRO), Departamento de Agronomia, Rua Padre Honorino João Muraro, 875, 85015- \\ 430 Guarapuava (PR), Brasil. \\ (4) UFLA, Departamento de Fitopatologia, 37200-000 Lavras (MG), Brasil. \\ (*) Autora correspondente: anaterciaa@yahoo.com.br
}

Recebido: 21/out./2013; Aceito: 14/abr./2014

Resumo

Com o objetivo de identificar o tipo de herança, o número de genes e os parâmetros genéticos e fenotípicos da resistência do acesso PI 595201 a um isolado de PRSV-W da região Norte do Brasil foi conduzido um experimento na área experimental do Departamento de Produção Vegetal da Universidade Federal do Tocantins, em condições de casa de vegetação. A partir do cruzamento entre a cultivar suscetível Crimson Sweet $\left(P_{1}\right)$ e o acesso resistente PI $595201\left(P_{2}\right)$ foi obtida a geração $F_{1}$ e as gerações segregantes, cujas plantas foram inoculadas e avaliadas quanto à resistência com base nos sintomas nas folhas. Foram avaliadas 48, 48, 80, 200, 100 e 100 plantas das gerações $P_{1}, P_{2}, F_{1}, F_{2}, R C_{11}$ e $R C_{12}$, respectivamente, em delineamento inteiramente casualizado com quatro repetições. A partir da análise de componentes de médias no controle da resistência determinaram-se dois genes, predominando os efeitos gênicos aditivos, seguido de efeitos de dominância incompleta no sentido de aumentar a resistência. As herdabilidades para a resistência, no sentido amplo e restrito, foram de 0,48 e 0,38, respectivamente.

Palavras-chave: Citrulus lanatus var. lanatus, Potyvirus, resistência genética, componentes principais.

\section{Inheritance of the resistance of the watermelon accession PI 595201 to a PRSV-W isolate from the State of Tocantins}

\begin{abstract}
Aiming to identify the type of inheritance, the number of genes and genetic and phenotypic parameters of PI 595201 access resistance to an isolate of PRSV-W in the North of Brazil, was conducted an experiment in the experimental area of the Department of Plant Production of the Universidade Federal do Tocantins, in a greenhouse. From the cross between the susceptible cultivar 'Crimson Sweet' $\left(P_{1}\right)$ and resistant access 'PI 595201' $\left(P_{2}\right)$ was obtained $F_{1}$ and segregating generations, whose plants were inoculated and evaluated for resistance based on leaf symptoms. Was evaluated 48, 48, 80, 200, 100 and 100 plants of $P_{1}, P_{2}$, $F_{1}, F_{2}, R C_{11}$ and $R_{12}$ generations, respectively, in a completely randomized design with four replications. From the analysis of medium components in the control of resistance were determined two genes, predominantly additive gene effects, followed by effects of incomplete dominance to increase the resistance. The heritability for resistance in broad and narrow sense were 0.48 and 0.38 , respectively.
\end{abstract}

Key words: Citrulus lanatus var. lanatus, Potyvirus, genetic resistance, principal components.

\section{INTRODUÇÃO}

O Estado do Tocantins é um dos principais produtores de melancia da regiẫo Norte do Brasil (Goiás, 2013), nele, o principal problema no cultivo é a ocorrência de viroses do gênero Potyvirus. O vírus da mancha anelar do mamoeiro, estirpe melancia (Pappaya Ringspot Virus-Strain
Watermelon, PRSV-W) é o mais importante, por reduzir a qualidade e a quantidade dos frutos (Vieira et al., 2010).

A espécie Citrulus lanatus var. lanatus (melancia) pertence à família Cucurbitaceae, na qual foram encontradas fontes de resistência a esse vírus. Em pepino (Cucumis 
sativus), a resistência ao PRSV-W é controlada por um gene dominante (Pitrat e Lecoq, 1983; Wai e Grumet, 1995) e em abobrinha (Cucurbita pepo) e abóboras (Curcubita maxima e C. moschata), por genes recessivos (Maluf et al., 1997). Em melancia a resistência também foi reportada como sendo controlada por um gene recessivo nos acessos africanos PI 244017, PI 482318 e PI 244019, sendo o alelo pvr o responsável nos três acessos (Guner et al., 2002).

O acesso de melancia PI 595201 (Citrullus lanatus var. lanatus) proveniente da Nigéria foi caracterizado como resistente ao PRSV-W (Guner et al., 2002). O controle da resistência foi reportado como complexo, com predomínio do efeito gênico aditivo e herdabilidade no sentido restrito de 0,7 , indicando que é possível realizar a seleção de plantas resistentes em populaçôes segregantes (Azevedo et al., 2012; Bezerra Júnior et al., 2007).

Apesar de esse acesso ser uma fonte de resistência genética ao PRSV-W, não foi elucidada sua eficiência a isolados oriundos da regiāo Norte do Brasil, nem sua herança nesse ambiente, pois a taxa de mutação dos vírus é elevada, podendo certos genes de resistência serem úteis em ambientes específicos - fato perceptível por a temperatura elevada dessa região favorecer a multiplicação dos vetores dos vírus.

O objetivo da pesquisa foi identificar o tipo de herança, o número de genes e os parâmetros genéticos e fenotípicos da resistência do acesso PI 595201 a PRSV-W do Estado do Tocantins.

\section{MATERIAL E MÉTODOS}

O experimento foi conduzido na Estação Experimental de Gurupi, pertencente ao Departamento de Produção Vegetal, Setor de Olericultura da Universidade Federal do Tocantins, em 2011, em condiçóes de casa de vegetação com telado antiafídeos.

Foi realizado o cruzamento da cultivar comercial suscetível Crimson Sweet $\left(\mathrm{P}_{1}\right.$ - genitor feminino) com o acesso resistente PI $595201\left(\mathrm{P}_{2}\right.$ - genitor masculino) e foram obtidas as populaçóes $\mathrm{F}_{1}, \mathrm{~F}_{2}, \mathrm{RC}_{11}$ e $\mathrm{RC}_{12}$ por meio de cruzamentos controlados As informaçóes dos genitores utilizados para a obtenção dessas populaçóes estão na tabela 1 .

A identificação do isolado de PRSV-W obtido de região produtora de melancia do Estado do Tocantins foi confirmada por teste sorológico Das-Elisa utilizando-se antissoros policlonais específicos para WMV, ZYMV e PRSV-W produzidos no Laboratório de Virologia Molecular da Universidade Federal de Lavras, a partir de Cucurbita pepo L. cv. Caserta inoculada via extrato vegetal tamponado com o isolado coletado na região. Para a preparação do inóculo, folhas de plantas de abóbora da cultivar Caserta infectadas com o isolado foram maceradas com auxílio de nitrogênio líquido, na presença de tampão fosfato monobásico dibásico 0,01 M, pH 7,0 e sulfito de sódio.
Tabela 1. Genitores utilizados para a obtenção das populaçóes $F_{1}$, $\mathrm{F}_{2}, \mathrm{RC}_{11}$ e $\mathrm{RC}_{12}$

\begin{tabular}{ll}
\multicolumn{1}{|c}{$\mathbf{P}_{1}-$ cultivar Crimson Sweet } & \multicolumn{1}{c}{$\mathbf{P}_{2}$ - acesso PI 595201} \\
\hline Suscetível ao PRSV-W & Resistente ao PRSV-W \\
\hline Fruto arredondado & Fruto arredondado \\
$\begin{array}{l}\text { Casca clara com estrias } \\
\text { verde-escuras }\end{array}$ & Casca branca \\
\hline Polpa vermelho intenso & Polpa branca \\
\hline Sabor muito doce & Pouco doce \\
\hline Poucas sementes & Excessivo número de sementes \\
\hline
\end{tabular}

As sementes dos parentais e das populaçóes foram semeadas em copos plásticos de $200 \mathrm{~mL}$ com paredes externas pintadas com tinta PVA preta, contendo uma mistura de terra de barranco (corrigido conforme análise de solo), substrato comercial e casca de arroz carbonizada, na proporção 1:1:1.

O delineamento experimental utilizado foi inteiramente casualizado com quatro repetiçóes. Os tratamentos foram formados, em cada repetiçáo, por 12 plantas do $\mathrm{P}_{1}, 12$ plantas do $\mathrm{P}_{2}, 20$ plantas da geração $\mathrm{F}_{1}, 60$ plantas da geração $\mathrm{F}_{2}$, 25 plantas da geraçáo $\mathrm{RC}_{11}$ e 25 plantas da geração $\mathrm{RC}_{12}$, de modo que os números totais de plantas avaliadas foram 48 , 48, 80, 200, 100 e 100, respectivamente para as geraçóes $\mathrm{P}_{1}, \mathrm{P}_{2}, \mathrm{~F}_{1}, \mathrm{~F}_{2}, \mathrm{RC}_{11}$ e $\mathrm{RC}_{12}$.

As inoculaçóes foram realizadas aos 35 e 40 dias após a semeadura. A primeira foi efetuada nas folhas cotiledonares e a segunda, nas duas primeiras folhas verdadeiras. As inoculaçôes foram realizadas por fricção da suspensão viral sobre a superfície das folhas com o polegar na presença de carborundum (400 mesh) e a seguir realizou-se a lavagem das folhas com água.

Foram realizadas quatro avaliaçóes de acordo com a severidade dos sintomas aos 15, 25, 35 e 45 dias após a primeira inoculação. As avaliaçôes se basearam em um sistema de notas proposta por Maluf et al. (1997), em que: 1 - Folhas sem sintomas; 2 - Poucas folhas com leve mosaico nos bordos; 3 - Maioria das folhas com mosaico e poucas bolhas; 4 - Maioria das folhas com mosaico, muitas bolhas e/ou folhas com leves deformações; 5 - Mosaico intenso e folhas com deformaçóes severas. Plantas com notas médias superiores a 2 foram consideradas suscetíveis. A eficiência da inoculação foi verificada pela inoculação de plantas náo infectadas de abóbora cv. Caserta e nos parentais.

Para avaliar o comportamento conjunto das populaçóes avaliadas em relação à resistência à doença foi realizada a análise de componentes principais, utilizando-se a matriz de variâncias e covariâncias amostrais das frequências das notas de resistência em cada geração. Esse método reduz as cinco dimensóes de notas da doença e seis populaçôes em duas, considerando todas as populaçóes $\left(\mathrm{P}_{1}, \mathrm{P}_{2}, \mathrm{~F}_{1}\right.$, $\mathrm{RC}_{1}, \mathrm{RC}_{2}$ ), permitindo fácil visualização da resposta das populaçóes à doença.

Com as médias e variâncias da resistência de cada população, foram estimados os seguintes parâmetros genéticos 
e fenotípicos: variância genética $\left(\sigma_{\mathrm{G}}^{2}\right)$, variância ambiental $\left(\sigma_{\mathrm{E}}^{2}\right)$, variância fenotípica $\left(\sigma_{\mathrm{F}}^{2}\right)$, variância aditiva $\left(\sigma_{\mathrm{A}}^{2}\right)$, variância de dominância $\left(\sigma_{\mathrm{D}}^{2}\right)$, herdabilidades no sentido amplo $\left(\mathrm{h}_{\mathrm{A}}^{2}\right)$ e no sentido restrito $\left(\mathrm{h}_{\mathrm{R}}^{2}\right)$. Também foram estimados os efeitos aditivos [a] e de dominância [d] dos genes que controlam o caráter, pelo método dos quadrados mínimos ponderados (Mather e Jinks, 1977).

As estimativas dos erros padróes foram obtidas de acordo com Vencovsky e Barriga (1992). Também foram estimados o grau médio de dominância (GMD) e o número mínimo de genes $(\eta)$, de acordo com Wright (1934). As análises foram feitas com auxílio do programa GENES (Cruz, 2006).

\section{RESULTADOS E DISCUSSÃO}

A análise de componentes principais explicou 95\% da variação observada no experimento, portanto as inferências geométricas têm alta acurácia para explicar os fenômenos genéticos. Observa-se que entre $\mathrm{P}_{1}$ (Crimson Sweet) e $\mathrm{P}_{2}$ (PI 595201) existe associaçáo inversa, ou seja, são contrastantes para resistência à doença, sendo a tendência oposta do sentido, conforme os vetores para o parental suscetível, e o segundo vetor para o parental resistente a PRSV-W (Figura 1).

$\mathrm{O}$ tamanho do vetor da população $\mathrm{F}_{2}$ é o dobro da geração $\mathrm{F}_{1}$, mostrando que existe maior variância na população $\mathrm{F}_{2}$, no entanto, ambas têm o mesmo sentido, indicando que as populaçôes têm média semelhante (Figura 1). Tetteh et al. (2013), avaliando folha e caule de melancia com resistência a oídio, também não observaram diferença entre as geraçóes $\mathrm{F}_{1}$ e $\mathrm{F}_{2}$, o que mostra que o controle genético não deve ser um gene com dominância completa. A dominância completa permitiria que o vetor da geração $\mathrm{F}_{1}$ formasse angulo que tende a zero com o um dos parentais. Esse fato indica que a resistência genética do acesso PI 595201 pode ser poligênica/oligogênica ou monogênica com modificadores

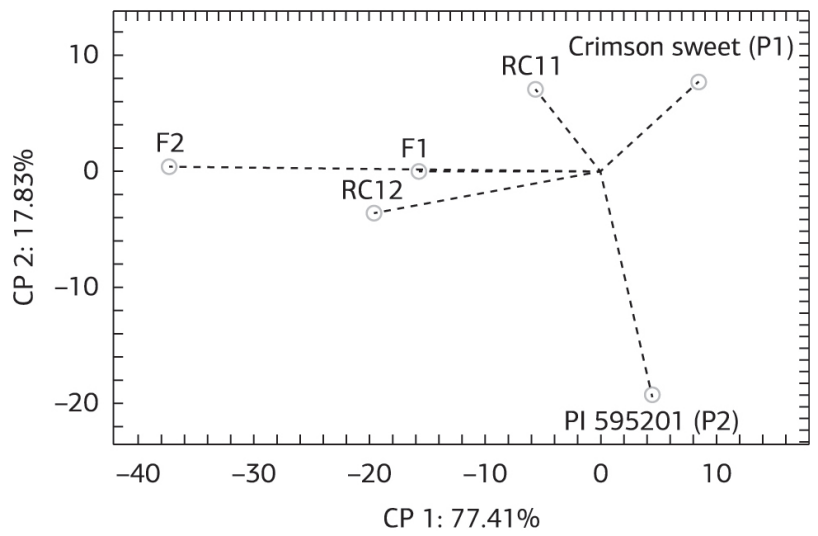

Figura 1. Análise de componentes principais a partir da matriz de variância e covariância para resistência ao $\mathrm{PRSV}-\mathrm{W}$ em populaçóes de melancia produzidas a partir da recombinação de Crimson Sweet x PI 595201. ou monogênica com dominância incompleta. Azevedo et al. (2012) afirmam que PI 595201 não possui uma simples herança monogénica para resistência ao PRSV-W.

A geração $\mathrm{RC}_{11}$ apresenta ortogonalidade com Crimson Sweet, o que indicaria independência das duas populaçóes para resistência a PRSV-W (Figura 1), mas como se trata de população de retrocruzamento, isso significaria rotação do vetor da geração $\mathrm{F}_{1}$ em direção à geração $\mathrm{P}_{1}$. Essa rotação foi próxima à metade do ângulo dos vetores da geraçáo $F_{1}$ e da geraçáo $\mathrm{P}_{1}$, indicando efeito aditivo para o controle da suscetibilidade. $\mathrm{O}$ vetor $\mathrm{RC}_{12}$ também rotacionou no sentido de $\mathrm{P}_{2}$ (Figura 1) mostrando provável efeito aditivo dos genes envolvidos.

As médias das populaçóes avaliadas em plantas do cruzamento entre Crimson Sweet e PI 595201 estáo apresentadas na tabela 2 , evidenciando-se que as médias dos parentais são contrastantes. Os erros da estimativa das médias dos parentais permitem verificar maior precisão para as plantas resistentes $(0,2)$ do que para plantas suscetíveis $(0,7)$. Esses resultados indicam que $\mathrm{P}_{1}$ é mais influenciada pelo ambiente do que a reaçáo do pai resistente $\mathrm{P}_{2}$. A média da população $\mathrm{F}_{1}$ é intermediária aos parentais e é igual à população $\mathrm{F}_{2}$ com $95 \%$ de confiança. As médias dos retrocruzamentos foram intermediárias entre a $F_{1}$ e os respectivos parentais, conforme a análise de componentes principais tinha revelado.

A análise de componentes de médias permitiu observar que no controle da resistência predominam os efeitos aditivos (Tabela 3), seguido dos efeitos de dominância, sendo essa dominância incompleta no sentido de aumentar

Tabela 2. Notas médias das populaçóes avaliadas em plantas do cruzamento entre Crimson Sweet e PI 595201 após inoculação mecânica com vírus da mancha anelar do mamoeiro, estirpe melancia (Pappaya Ringspot Virus-Strain Watermelon - PRSV-W)

\begin{tabular}{|ccc|}
\hline Populações & N & Médias \\
\hline $\mathrm{P}_{1}$ & 48 & $4,54 \pm 0,735^{(1)}$ \\
\hline $\mathrm{P}_{2}$ & 48 & $1,06 \pm 0,214$ \\
$\mathrm{~F}_{1}$ & 80 & $2,38 \pm 0,169$ \\
$\mathrm{~F}_{2}$ & 200 & $2,46 \pm 0,869$ \\
\hline $\mathrm{RC}_{11}$ & 100 & $3,13 \pm 0,732$ \\
\hline $\mathrm{RC}_{12}$ & 100 & $2,25 \pm 0,564$ \\
\hline
\end{tabular}

(1) Erro da estimativa $\alpha=0,05$.

Tabela 3. Estimativa dos componentes de médias, grau médio de dominância (GMD) e número de genes ( $\eta$ ) no controle da resistência ao PRSV-W em melancia a partir do cruzamento entre Crimson Sweet e PI 595201

\begin{tabular}{cc}
\hline$M$ & $2,60 \pm 0,064$ \\
\hline$[a]$ & $1,22 \pm 0,063$ \\
{$[d]$} & $-0,25 \pm 0,11$ \\
$x^{2}$ & $0,07^{\text {ns }}$ \\
\hline$M D$ & $-0,205$ \\
$\eta$ & 1,86 \\
\hline
\end{tabular}

M: média geral; [a]: efeitos aditivos; [d]: efeitos de dominância. 
Tabela 4. Estimativa dos parâmetros genéticos, fenotípicos e herdabilidade da reação de plantas de melancia ao PRSV-W do cruzamento entre Crimson Sweet e PI 595201

\begin{tabular}{ccccccccc} 
& \multicolumn{4}{c}{ Componentes de variância } & \multicolumn{2}{c}{ Herdabilidades } \\
\cline { 2 - 8 } Cruzamentos & $\sigma_{\mathrm{G}}^{2}$ & $\sigma_{\mathrm{A}}^{2}$ & $\sigma_{\mathrm{D}}^{2}$ & $\sigma_{\mathrm{E}}^{2}$ & $\sigma_{\mathrm{F}}^{2}$ & $\mathrm{~h}_{\mathrm{A}}^{2}$ & $\mathrm{~h}_{\mathrm{R}}^{2}$ \\
CS x PI 595201 & 0,386 & 0,302 & 0,062 & 0,415 & 0,801 & 0,48 & 0,38
\end{tabular}

CS: Crimson Sweet; $\sigma_{\mathrm{G}}^{2}, \sigma_{\AA}^{2}, \sigma_{\mathrm{D}}^{2}, \sigma_{\mathrm{E}}^{2}, \sigma_{\mathrm{F}}^{2}$ : variância genética, variância aditiva, variância dominante, variância ambiental e variância fenotípica, respectivamente.

a resistência - resultados similares foram encontrados por Azevedo et al. (2012).

Os parâmetros genéticos estimados através do modelo aditivo-dominante foram suficientes para explicar o controle genético da reação ao PRSV-W, não havendo evidências de interações alélicas entre os genes que condicionam a resistência, conforme pode ser verificado pela nãosignificância do $\chi^{2}$ (Tabela 3), corroborando resultados de Tetteh et al. (2013), não se necessitando, assim, da inclusáo de outros modelos. O grau médio de dominância foi estimado em -0,7, sendo indicativo de dominância no sentido de aumentar a resistência ao PRSV-W (Tabela 3).

O número de genes que controla a resistência no acesso PI 595201 foi estimado em dois, com predomínio de efeitos aditivos (Tabela 3). O controle genético da resistência desse acesso é variável para outros vírus e isolados de PRSV-W de outros ambientes. Nesse acesso foi encontrado um gene recessivo (Strange et al., 2002), herança predominantemente aditiva para diferentes isolados de PRSV-W (Azevedo et al., 2012), quatro genes para o WMV (Bezerra Júnior et al., 2008) e um gene recessivo para ZYMV (Xu et al., 2004).

Todos os resultados indicam herança complexa, em detrimento da monogênica típica, corroborando resultados de Azevedo et al. (2012), o que indicaria que o mecanismo de resistência da planta poderia ser o mesmo.

A partir das estimativas dos componentes de variância fenotípica observou-se que a variação ambiental foi a de maior magnitude, diminuindo o valor da herdabilidade, cujas estimativas foram inferiores a 0,5 (Tabela 4), indicando que a resistência é influenciada pelo ambiente.

\section{CONCLUSÃO}

O controle da resistência ao PRSV-W em melancia está determinado por dois genes, predominando os efeitos gênicos aditivos, seguidos de efeitos de dominância incompleta no sentido de aumentar a resistência.

A herdabilidade da resistência ao vírus PRSV-W foi baixa, portanto para utilizar essa fonte de resistência deve-se realizar teste de progênies nas etapas iniciais de seleção para obtenção de famílias homozigotas para resistência a essa virose.

\section{AGRADECIMENTOS}

Ao Conselho Nacional de Desenvolvimento Científico e Tecnológico - CNPq, pela concessão de bolsa e auxílio financeiro. À Capes, pela bolsa do programa nacional de pós-doutorado - PNPD.

\section{REFERÊNCIAS}

AZEVEDO, S.M.; MALUF, W.R.; FARIA, M.V.; RESENDE, J.T.V.; MENEZES, C.B.; NASCIMENTO, I.R. Inheritance of resistance to the Papaya ringspot virus-watermelon strain (PRSV-W) from watermelon accession 'pi 595201'. Crop Breeding and Applied Biotechnology, v.12, p.67-75, 2012. http://dx.doi.org/10.1590/ S1984-70332012000100009

BEZERRA JÚNIOR, J.E.A.; MALUF, W.R.; FIGUEIRA, A.R.; BARGUIL, B.M. Herança da resistência ao Watermelon mosaic virus em melancia (Citrullus lanatus L.). Fitopatologia Brasileira, v.31, p.302305, 2008. http://dx.doi.org/10.1590/S0100-41582006000300010

BEZERRA JÚNIOR, J.E.A.; FIGUEIRA, A.R.; MALUF, W.R. Seleção de genótipos de melancia resistentes ao watermelon mosaic virus e ao papaya ringspot vírus. Ciência e Agrotecnologia, v.31, p.15631568, 2007. http://dx.doi.org/10.1590/S1413-70542007000500044

CRUZ, C.D. Programa Genes: Biometria. Viçosa: Editora UFV, 2006. 382p.

GOIÁS. Secretaria de Estado da Agricultura, Pecuária e Irrigação - SEAGRO. Disponível em: <http://www.agronegocio. goias.gov.br/index.php?.pg=arqdoc\&id_categoria=33>. Acesso em: 20 ago. 2013

GUNER, N.; STRANGE, E.B.; WEHNER, T.C.; PESICVANESBROECK, Z. Papaya ringspot virus type-w resistance in watermelon. In: MAYNARD, N. (Ed.). Proc. Cucurbitaceae 2002. Alexandria: Proc. Press, 2002. p.238-246. PMid:11998441.

MALUF, W.R.; PEREIRA, J.J.; FIGUEIRA, A.R. Inheritance of resistance to the Papaya ringspot virus-watermelon strain from two different accessions of winter squash Cucurbita maxima Duch. Euphytica, v.94, p.163-168, 1997. http://dx.doi.org/10.1023/A:1002998216465

MATHER, K.; JINKS, J.L. Introduction to biometrical genetics. Ithaca: Cornell University Press, 1977. 213p. http://dx.doi.org/10.1007/97894-009-5787-9

PITRAT, M.; LECOQ, H. Inheritance of zucchini yellow mosaic virus resistance in Cucumis melo L. Euphytica, v.33, p.57-61,1983. http:// dx.doi.org/10.1007/BF00022750

STRANGE, E.B.; GUNER, N.; PESIC-VANESBROECK, Z.; WEHNER, T.C. Screening the watermelon germplasm collection for resistance to (Papaya Ringspot Virus Type-W). Crop Science, v.42, p.1324-1330, 2002. http://dx.doi.org/10.2135/cropsci2002.1324

TETTEH, A.Y.; WEHNER, T.C.; DAVIS, A.R. Inheritance of resistance to the new race of powdery mildew in watermelon. Crop Science, v.53, p.880-887, 2013. http://dx.doi.org/10.2135/cropsci2012.07.0453

VENCOVSKY, R.; BARRIGA, P. Genética biométrica no fitomelhoramento. Ribeirão Preto: Sociedade Brasileira de Genética, 1992. 496p. 
VIEIRA, J.V.; ÁVILA, A.C.; SILVA, G.O. Avaliação de genótipos de melancia para resistência ao Papaya ringspot vírus, estirpe melancia. Horticultura Brasileira, v.28, p.7-11, 2010. http://dx.doi.org/10.1590/ S0102-05362010000100002

WAI, T.; GRUMET, R. Inheritance of resistance to the watermelon strain of Papaya ringspot virus in the cucumber line TMG-1. HortScience, v.30, p.338-340, 1995.
WRIGHT, S. The results of crosses between inbred strains of Guinea pigs, differing in number of digits. Genetics, v.19, p.537-551, 1934. PMid:17246736 PMCid:PMC1208512.

XU, Y.; KANG, D.; SHI, Z.; SHEN, H.; WEHNER, T. Inheritance of resistance to Zucchini Yellow Mosaic Virus and Watermelon Mosaic Virus in watermelon. Journal of Heredity, v.94, p.498-502, 2004. PMid:15475395. http://dx.doi.org/10.1093/jhered/esh076 